\title{
A Fuzzy Based Approach for PWM Inverter fed Induction Motor V/f speed control
}

\author{
Ashwini M. Patil, Prof. Thorat R. A., Asst. Prof. Kadam M. M.
}

\begin{abstract}
Induction motors are the most widely used for appliances, industrial control, and automation; however, many applications need variable speed operations. The rapid development of power electronics controllers in recent years has attracted the attention of researchers for making use of flexible characteristics of an induction motor in variable frequency drives. It presents a compact embedded fuzzy system for three-phase induction motor scalar speed control. The control strategy consists of keeping constant the voltage frequency ratio of the induction motor supply source

Keywords: Fuzzy control, induction motor, real time system
\end{abstract}

\section{Introduction}

Most of all industrial motor applications use AC induction motors. The reasons for this include high robustness, reliability, low price and high efficiency, in order to reduce costs of operation and to maximize long term profit gains for the user. Many industrial processes such as assembly lines must operate at different speeds for different products. Therefore speed control is essential for AC drives.

However, induction motors do not inherently have the capability of variable speed operation. Due to this reason, the recent developments in speed control methods of the induction motor have led to their large scale use in almost all electrical drives. . While there are different methods for control, Variable Frequency Drive (VFD) is the most common method of speed control. The VFD control system is considered due to its wide application in industrial fields.

Power electronic control achieves smooth variation of voltage and frequency of the ac output. This when fed to the machine is capable of running at a controlled speed. With the advancement in the semiconductor fabrication technology, both the size and the price of semiconductors have gone down drastically. This means that the motor user can replace an energy inefficient mechanical motor drive and control system with a VFD. The VFD not only controls the motor speed, but can improve the motor's dynamic and Steady state characteristics as well. In addition, the VFD can reduce the system's average energy consumption.

The base speed of the induction motor is directly proportional to the supply frequency and the number of poles of the motor. Since the number of poles is fixed by design, the best way to vary the speed of the induction motor is by varying the supply frequency. The torque developed by the induction motor is directly proportional to the ratio of the applied voltage and the frequency of supply. The fuzzy based VFD is described in the second section. Different issues \& solutions related to proposed method are described in third section. Summary of the technique for induction motor speed control described in the last section.

\section{Fuzzy Based V/F Speed Control System}

The speed control of induction motor is carried out by maintaining constant the voltage-frequency ratio in order to avoid the air-gap flux variations. If the supply voltage is varied without frequency adjustment, the induction motor can operate in the flux saturation region or with a weakened field. There are different methods for control, Variable Voltage Variable Frequency or V/F is the most common method of speed control in open loop. Scalar control presents a simple structure characterized by low steady-state error. The constant voltagefrequency scalar control system is considered due to its wide application in industrial fields. The block diagram of the proposed fuzzy-control system is shown in Fig.1, The system will be responsible for measuring the TIM shaft angular speed, achieving the fuzzy-control algorithm and generating the sinusoidal modulated PWM signal in order to turn on three phase PWM inverter. The motor speed signal of Induction motor is compared with the reference speed provides the inputs of fuzzy logic controller with the speed error and speed error variation.

The variable frequency drive controller is a solid state power electronics conversion system consisting of three distinct sub-systems: a rectifier bridge converter, a direct current (DC) link, and an inverter. Three phase input source is a common electrical system that is used in commercial and industrial installations. 


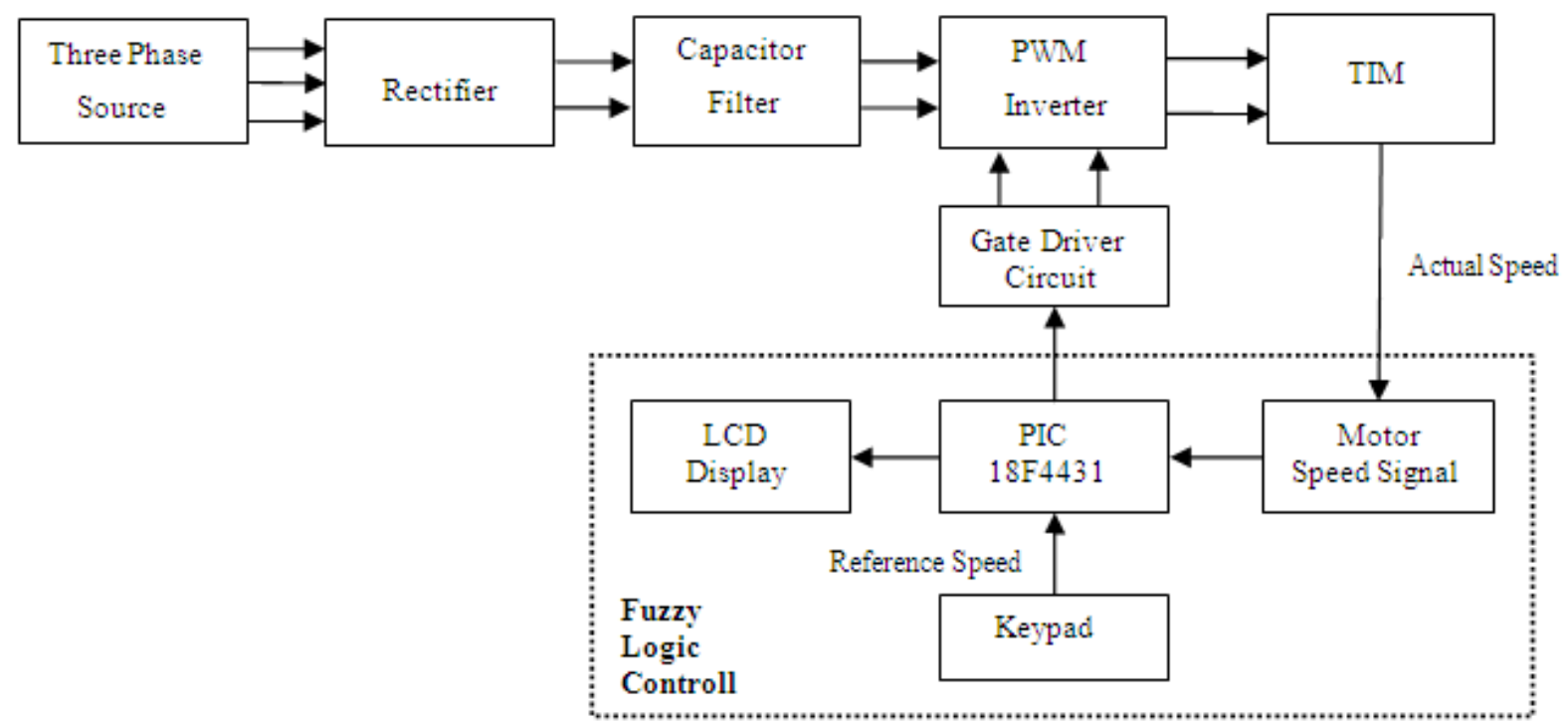

Fig.1 Fuzzy-control system block diagram

Rectifier is a device or circuit that converts alternating current (ac) to direct current (dc), which allow current in one direction only. An inverter is simply a direct current (dc) to alternating current (ac) converter. Inverter driven with PWM pulses through gate driver circuit, it uses solid state relay (SSR). Overview of Variable Frequency Drive control platforms is shown in Fig.2

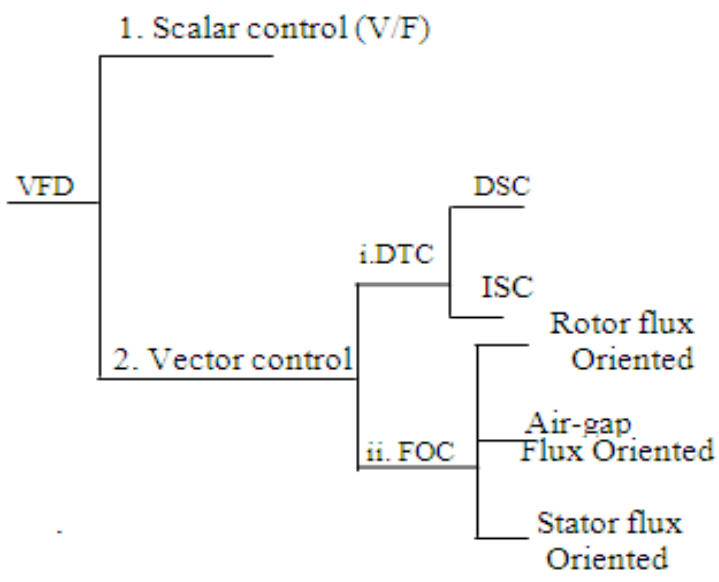

Fig.2 VFD Control platform

DTC - Direct torque control

FOC - Field oriented control

DSC- Direct self control

ISC- Indirect self control

Several studies have been carried out in the field of vector control system [1] due to its better dynamic response. However; scalar control presents a simple structure characterized by low steady-state error. Therefore, the constant voltage-frequency (V/f) scalar control system [3] will be considered due to its wide application in industrial fields.

The three phase induction motor is supplied by a PWM inverter with a fundamental frequency and equivalent voltage, such that v/f ratio will kept constant. Fuzzy logic controller (FLC) is an expert system implementing a part of a human operators or process engineer's expertise which is not incorporated by conventional differential-equation based controllers. It proves to be superior whenever a model of the process is unavailable, it gives the better performance compared to conventional controllers. 


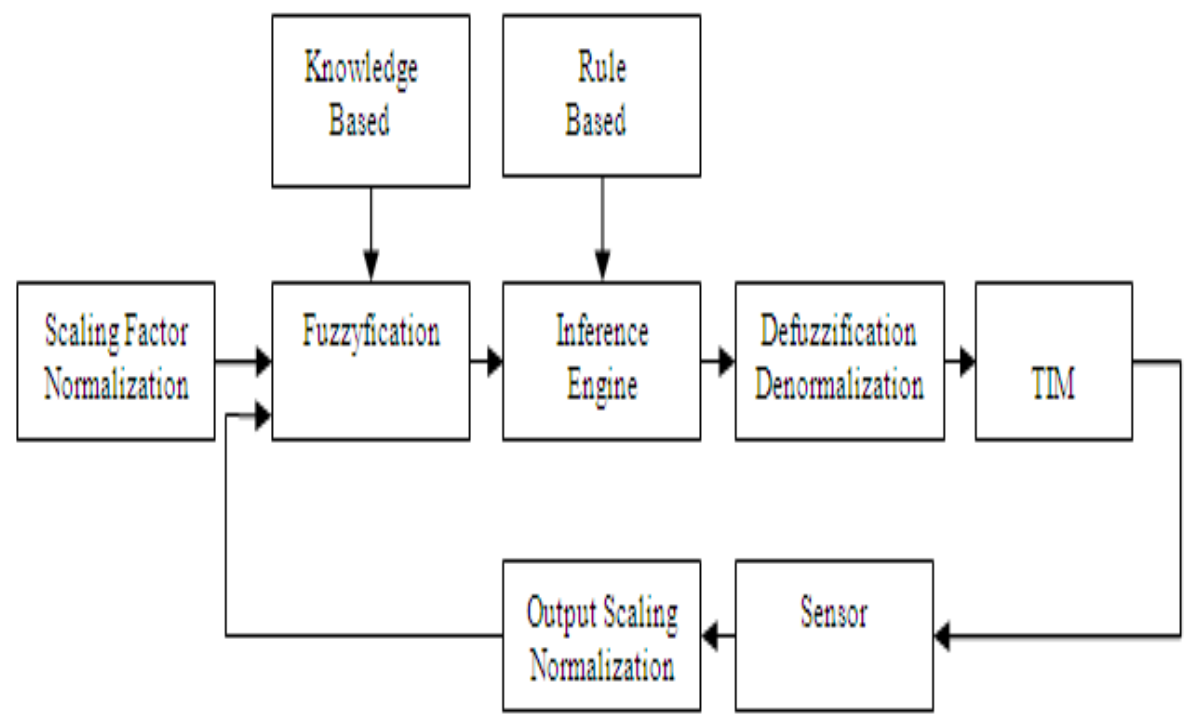

Fig.3 Fuzzy Logic Controller

The embedded fuzzy system proposed here will be designed to reduce memory-space requirements and computational effort for real-time applications for a real-time hardware application, which requires minimal computational costs, a possible solution is to store a matrix of input-output relation in memory space as a lookup table structure. There would then be no need to carry out any computation involved in a fuzzy inference system, since it could be achieved by means of simple table indexing. However, this method would demand a large memory space that could increase project costs. On the other hand, in an application where a minimal memory requirement is desired, the whole fuzzy inference process can be calculated online, avoiding storing membership functions in memory.

As a result, in many applications, it is recommended that memory requirements and computational effort be traded off, in order to achieve the best structure-satisfying requisites, i.e., project costs and real-time performance for a particular application

\section{Methodology}

\section{A. Fuzzy Logic Controller:}

Fuzzy logic controller (FLC) is an expert system implementing a part of a human operators or process engineer's expertise which is not incorporated by control actions employing fuzzy implication and the rules of inference in fuzzy logic. Defuzzification is a scale mapping, which converts the range of values of output variables into corresponding universe of discourse and also yields a non-fuzzy control action from an inferred fuzzy control action. This transformation is performed by Membership Functions (MF). In FLC, number of MF and their shapes are initially determined by user.

The knowledge base module of fuzzy controller contains knowledge about all input and output fuzzy partitions. It includes the terms set and corresponding membership functions defining the input variables to the fuzzy rule base system and the output variables, or, control actions, to the conventional differential-equation based controllers. It proves to be superior whenever a model of the process is unavailable, it gives the better performance compared to conventional controllers. Today, there are number of products in the market which are controlled by fuzzy logic in which different types of FLC are used, the block diagram of the fuzzy logic controller is shown in Fig.3. In general this type of FLC contains four main parts, two of which perform transformations; which are:

a) Fuzzyfier

b) Knowledge base

c) Inference engine

d) Defuzzyfier 
The steps in designing a simple fuzzy logic control system are as follows,

a) Identify the variables (input, outputs, and states) of the plant.

b) Partition the universe of discourse or the interval spanned by each variables into a number of fuzzy subsets, assigning each a linguistic label (subsets include all the elements in the universe).

c) Assign or determine a membership function for each fuzzy subset.

d) Assign the fuzzy relationships between the inputs or states fuzzy subsets on the one hand and the outputs fuzzy subsets on the other hand, thus forming the rule-base.

e) Choose appropriate scaling factors for the input and output variables in order to normalize the variables to the $[0,1]$ or the $[-1,1]$ interval.

f) Fuzzify the inputs to the controller.

g) Use fuzzy approximate reasoning to infer the output contributed from each rule.

h) Aggregate the fuzzy outputs recommended by each rule.

i) Apply defuzzification to form a crisp output.

\section{B. Fuzzy Control System Rule Database:}

In order to design a simplified embedded fuzzy inference system for the V/f induction-motor control, the triangular and symmetrical membership functions shown in Fig.4 used.

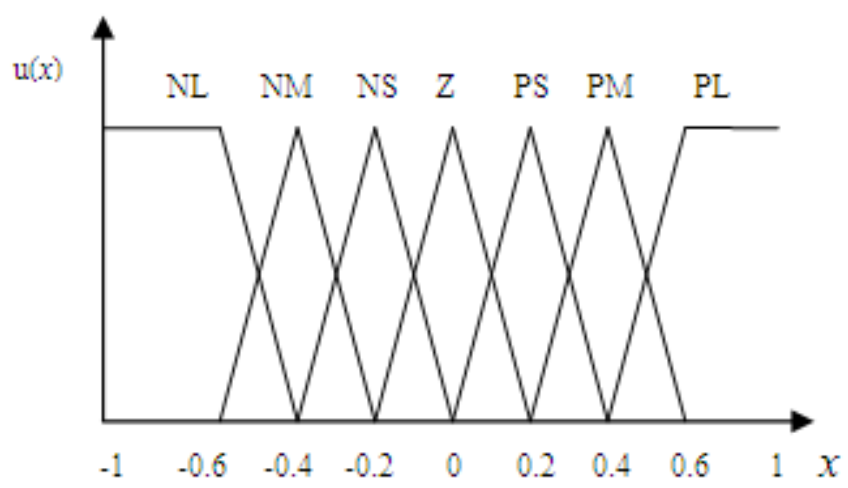

Fig.4 Membership functions of the fuzzy-control system.

All the linguistic variables of the fuzzy-control system (speed error, speed-error variation, and frequency variation) are scaled into a common discourse universe with values between [-1, 1]. As a consequence, it is possible to map all the variables simultaneously with a unique set of membership functions.

- Input Linguistic variables: Speed error and Speed error variation

- Output Linguistic variables: Frequency variation

- The linguistic terms are described as follows:

NL-"Negative Large";

NM-"Negative Medium" and

NS-"Negative Small";

ZZ- "Zero"

PS-“Positive Small";

PM-"Positive Medium" and

PL- "Positive Large"

The discourse universe of the "speed-error" linguistic variable was designed for the $[-200,200] \mathrm{r} / \mathrm{min}$ interval. It was therefore normalized to $[-1,1]$ by dividing the speed-error signal before the fuzzification process, as shown in Fig.5. The "speed-error variation" linguistic variable was adjusted to a discourse universe of $[-150,150] \mathrm{r} / \mathrm{min}$, which was divided by 150 to take the signal into the $[-1,1]$ interval. In a similar way, the "frequency variation" output linguistic variable with a $[-1,1]-\mathrm{Hz}$ interval was multiplied by three to take it to the $[-3,3]-\mathrm{Hz}$ interval.

Fuzzy rules can be implemented based on expert knowledge of the control process, which is treated linguistically in an "if-then" structure. As a consequence, it dispenses with the detailed or precise knowledge of the mathematical model that represents the control plant. The rules were based on the studies conducted in [10], whose first two fuzzy rules are represented as follows: 
1. If (speed error is NL) and

(Speed-error variation is NL)

Then (frequency variation is $\mathbf{N L}$ )

2. If (speed error is NL) and

(Speed-error variation is NM)

Then (frequency variation is $\mathbf{N L}$ )

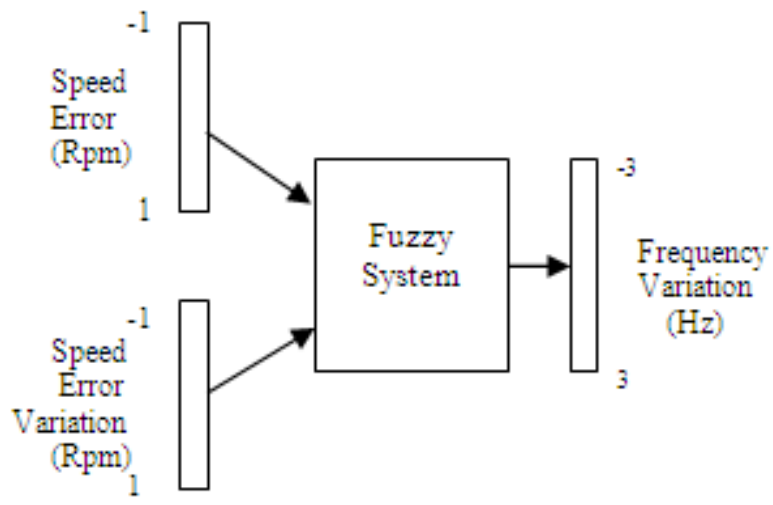

Fig.5 Normalization of the discourse universe

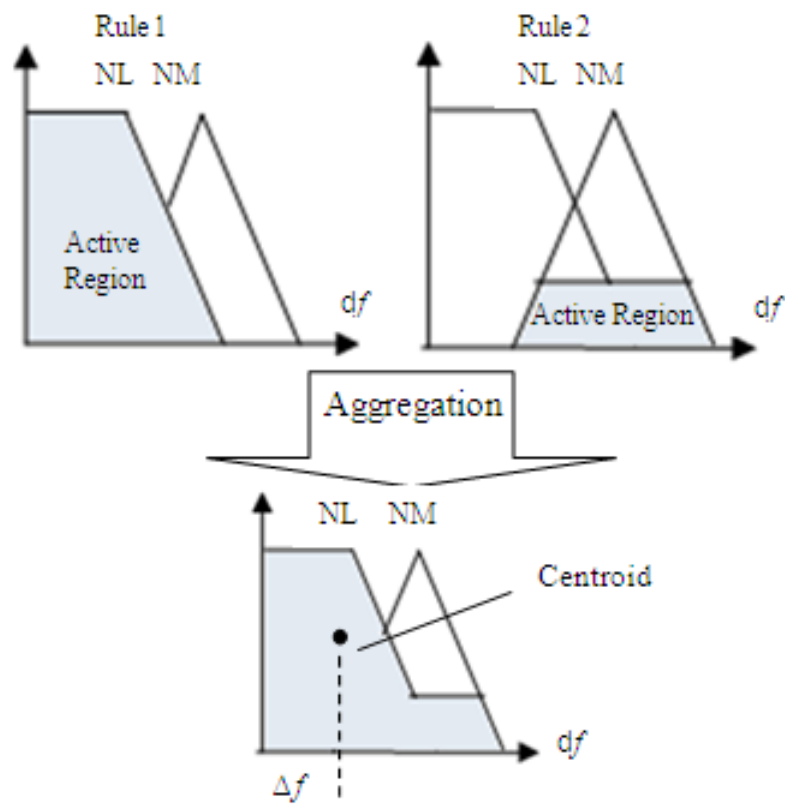

Fig.6. Mamdani fuzzy inference implication method

After determining the active regions of all rules activated by input variables ' $\omega$ er' and 'dwer', the aggregation operation carried out. As a result, a union of all individual contributions of each active rule was achieved, according to Fig. 6.

\section{Mamdani Fuzzy Inference Implication Method:}

The Mamdani operator, shown in Fig.4, is chosen due to its computational simplicity. In this generic

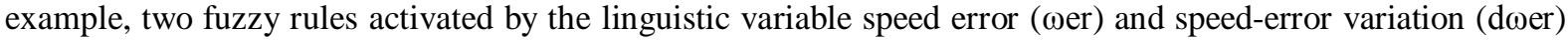
are illustrated. For "Rule 1" the linguistic terms activated by wer and dwer are NL and NM, respectively. The Mamdani implication method achieves the minimum between membership values of each term in order to obtain the active output region associated with "Rule 1 (NL)," as shown in Fig.6.The output value $(\Delta \mathbf{f})$ represents Fundamental frequency of IM supply voltage. 


\section{B. Sinusoidal PWM Signal Generation:}

Sinusoidal reference signal is proportional to IM supply voltage, therefore V/F ratio is obtained by controlling reference signals $(\Delta \mathrm{f})$ amplitude and frequency through Fuzzy logic. A triangular carrier is defined by controller timer, whose counter is increased according to the internal oscillator frequency. This counter (T1CNT) is reset when it matches the T1PR register value, which defines the carrier frequency. Therefore, while the T1CNT value is less than one Compare register (CMPR), the output is activated at a high level.

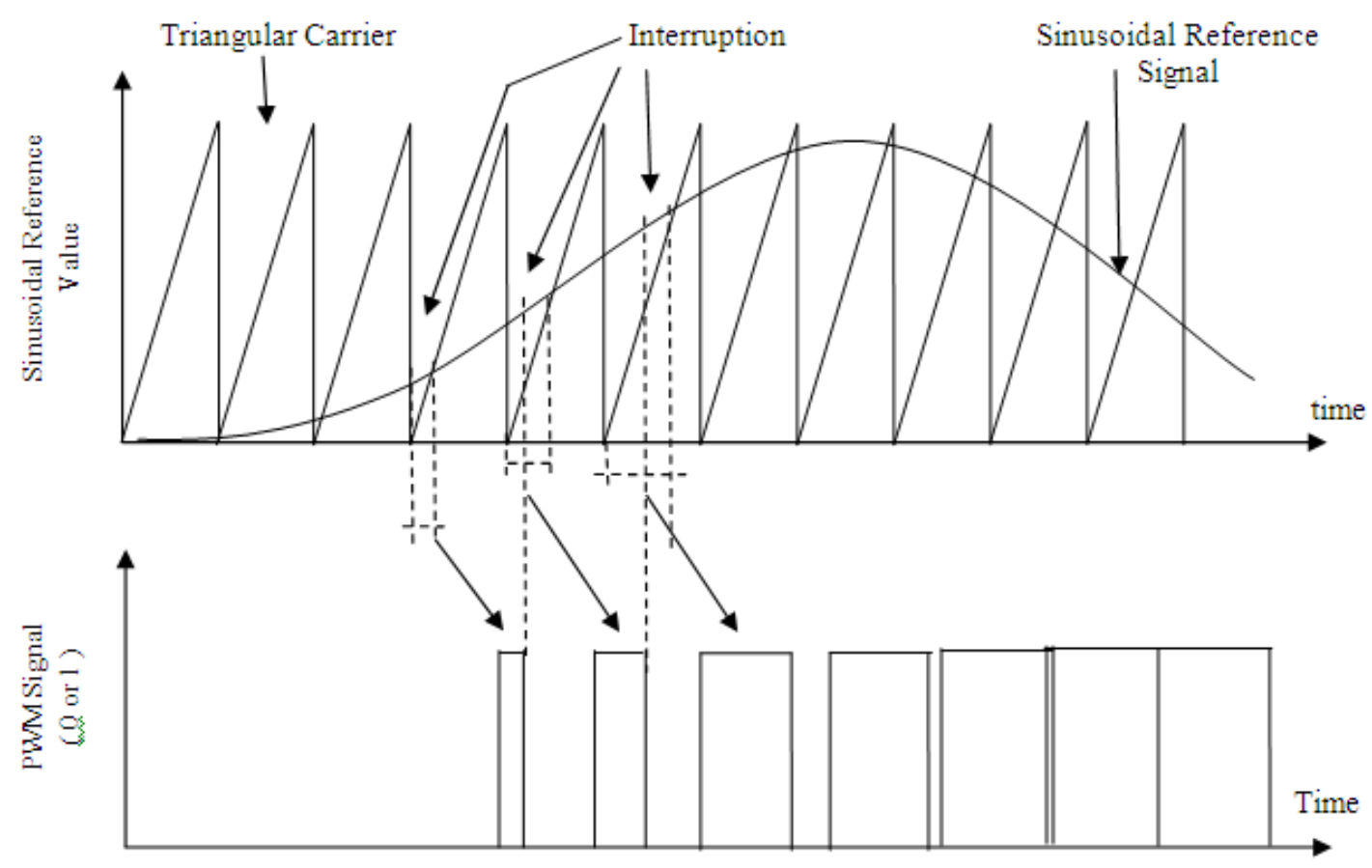

Fig.7 Sinusoidal PWM signal generation

As shown in Fig.7, the algorithm determines the new CMPR value proportional to the sinusoidal reference amplitude for the next period. The sinusoidal reference signal was stored in the memory space as a lookup table structure. As it is proportional to the induction-motor supply voltage, the V/f ratio is obtained by controlling its amplitude and frequency with help of $\Delta$ f, i.e. output value of fuzzy logic controller.

\section{Conclusion}

The proposed fuzzy-control system will be an acceptable alternative method for V/F common control applications A low-cost V/F speed control solution. Additional on-chip resources, like multiple timers and ADC, allow users to easily implement safety and control features

The analysis with control platforms such as Direct Torque Control [4], direct self control [5], Indirect Vector Control [1], Stator Flux Control [6] and Scalar control [3] clears that, the proposed embedded fuzzy system for three phase induction motor scalar speed control is having a simplified architecture which reduces memory-space requirements.

\section{References}

[1] Suman Maiti, Vimlesh Verma and Chandan Chakraborty "an adaptive speed sensor less induction motor Drive with artificial neural network for Stability enhancement" IEEE transactions on industrial informatics, vol. 8, no. 4, november 2012.

[2] Chintan patel, rajeevan P. P., anubrata dey andrijil ramchand "Fast direct torque control of an open-end Induction motor drive using 12-sided Polygonal voltage space vectors" IEEE transactions on power electronics, vol. 27, no. 1, january 2012.

[3] Marcelo Suetake, Ivan N. da Silva and Alessandro Goedtel, "Embedded DSP-Based Compact Fuzzy System and Its Application for Induction-Motor V/f Speed Control" IEEE transactions on industrial electronics, vol. 58, no. 3, march 2011.

[4] Yongchang Zhang, Jianguo Zhu, Zhengming Zhao,Wei Xu and David G. Dorrell "An Improved Direct Torque Control for ThreeLevel Inverter-Fed Induction Motor Sensorless Drive" IEEE Transactions On Power Electronics, Vol. 27, No. 3, March 2012.

[5] Sayeed A. Mir, Donald S. Zinger and Malik E. Elbuluk, "Fuzzy Controller For Inverter Fed Induction Machines" IEEETransactions On Industry Applications, Vol. 30. No. 1, Januaryi -february 1993

[6] Epaminondas D. Mitronikas, Athanasios N. Safacas And Emmanuel C. Tatakis, “A New Stator Resistance Tuning Method For Stator-Flux-Oriented Vector-Controlled Induction Motor Drive" IEEE Transactions On Industrial Electronics, Vol. 48, No. 6, December 2001 
[7] S. Xiang-Dong, K. Kang-Hoon, Y. Byung-Gyu, and M. Matsui, "Fuzzy logic- based V/f control of an induction motor for a DC grid power leveling system using flywheel energy storage equipment," IEEE Trans. Ind. Electron., vol. 56, no. 8, pp. 3161-3168, Aug. 2009.

[8] F. Zidani, D. Diallo, M. E. H. Benbouzid, and R. N. Saïd, "A fuzzy-based approach for the diagnosis of fault modes in a voltage-fed PWM inverter induction motor drive,” IEEE Trans. Ind. Electron., vol. 55, no. 2, pp. 586-593, Feb. 2008.

[9] Bin Lu, Thomas G. Habetler, and Ronald G. Harley,"A Survey of Efficiency- Estimation Methods for In-Service Induction Motors" IEEE transactions on industry applications, vol. 42, no. 4, july/august 2006.

[10] M. Nasir Uddin, Tawfik S. Radwan and M. Azizur Rahman,’Performances of Fuzzy-Logic-Based Indirect Vector Control for Induction Motor Drive" IEEE transactions on industry applications, vol. 38, no. 5, september/october 2002.

[11] Epaminondas D. Mitronikas, Athanasios N. Safacas and Emmanuel C. Tatakis,"A New Stator Resistance Tuning Method for StatorFlux-Oriented Vector Controlled Induction Motor Drive", IEEE transactions on industrial electronics, vol. 48, no. 6, December 2001

[12] E.Bim, "Fuzzy optimization for rotor constant identification of an indirect FOC induction motor drive," IEEE Trans. Ind Electron., vol. 48, no. 6, pp. 1293-1295, Dec. 2001.

[13] P. P. Cruz and J. P. S. Paredes, “Artificial intelligence applications in direct torque control,” in Proc. 5th Int. Conf. PEDS, 2003, vol. 2, pp. 1208-1212.

[14] A. Tae-Chon, K. Yang-Won, H. Hyung-Soo, and W. Pedricz, "Design of neuro-fuzzy controller on DSP for real-time control of induction motors," in Proc. IFSA World Congr., 20th NAFIPS Int. Conf., 2001, vol. 5, pp. 3038-3043.

[15] G. El-Saady, A. M. Sharaf, A. Makky, M. K. Sherbiny, and G. Mohamed,"A high performance induction motor drive system using fuzzy logic controller,” in Proc. 7th Mediterranean Electrotech. Conf., 1994, vol. 3, pp. 1058-1061.

[16] R. Krishnan, Electric Motor Drives - Modeling, Analysis, and Control. Upper Saddle River, NJ: Prentice-Hall, 2001.

[17] A. M. Trzynadlowski, Control of Induction Motors. New York: Academic, 2001.

[18] W. Dazhi, T. Renyuan, J. Hui and Y. Jie, "Sensorless-speed controlstrategy of induction motor based on artificial neural networks",FifthWorld Congress on Intelligent Control and Automation (WCICA), vol. 5,pp. 4467-4471, 2004. 